\title{
A Obra de Carlos Hasenbalg e seu Legado à Agenda de Estudos sobre Desigualdades Raciais no Brasil*
}

Márcia Lima

Universidade de São Paulo (USP), São Paulo, SP, Brasil. E-mail: m.rlima@uol.com.br

\begin{abstract}
T o dia 5 de outubro de 2014 faleceu, em Buenos Aires, nosso queri1 do amigo, mestre e parceiro Carlos Hasenbalg. Argentino de nascimento, adotou o Brasil não apenas como seu país de residência por trinta e oito anos (1967-2005), mas também como foco de sua preocupação intelectual, investigando por décadas o tema das desigualdades raciais no país. Na véspera de seu falecimento, Carlos e eu conversamos por telefone e organizamos minha ida a Buenos Aires para uma rápida visita. Sempre extremamente organizado, pediu-me que enviasse por e-mail todos os detalhes da minha viagem. Nossa última conversa foi fazendo planos para um futuro próximo que não se realizou. Ele me pediu que fosse o mais rápido possível, mas, no dia seguinte, ele se foi.

Impossível não lembrar, na narrativa da despedida, da nossa primeira conversa. Foi quando Carlos resolveu me contratar como sua assistente de pesquisa. Neste primeiro encontro, disse-me que para trabalhar com ele era necessário ter organização, disciplina e método. Mesmo sem ter nenhuma destas características, trabalhamos juntos por mais de uma década, mas eram estas palavras que Carlos sempre usava após cada encontro de trabalho. Nelson do Valle Silva, amigo e parceiro intelectual, era o contraponto necessário e vital para o jeito metódico
\end{abstract}

\footnotetext{
* Não poderia deixar de registrar o meu agradecimento aos editores de DADOS - Revista de Ciências Sociais pelo honroso convite para participar desta homenagem.
}

DADOS - Revista de Ciências Sociais, Rio de Janeiro, vol. 57, no-4, 2014, pp. 919 a 933. 
de Carlos. Estilos pessoais diferentes, mas intelectualmente muito afinados, Carlos e Nelson construíram não apenas uma parceria acadêmica, mas uma amizade, um respeito e uma admiração mútuos que considero raros no mundo acadêmico vigente. O primeiro trabalho desta parceria foi "Industrialização e Estrutura de Emprego no Brasil: 1960-1980". O texto foi escrito para o Seminário "Oportunidades e Limites da Sociedade Periférica: O Caso do Brasil", realizado em Nova Friburgo, em 1983. O trabalho fez sucesso. Foi publicado em inglês no livro State and Society in Brazil: Continuity and Change, em 1987, e foi o capítulo de abertura do primeiro livro da dupla, Estrutura Social, Mobilidade e Raça, publicado em 1988.

Tive o privilégio de trabalhar com os dois por mais de uma década e com eles aprendi não apenas os ofícios do sociólogo, mas a importância da parceria e da interlocução respeitosa. Assim, com pouquíssima organização, disciplina ou método, me debruço à difícil tarefa de registrar a morte e homenagear a vida de Carlos Hasenbalg. Graças a tudo o que me ensinou, estou na privilegiada posição de falar sobre ele neste momento.

Neste texto, traço um breve relato da trajetória de Carlos dando ênfase a dois aspectos que considero marcantes na sua vida intelectual. O primeiro, a sua importância na consolidação do campo de investigação sobre desigualdades raciais no Brasil, atuando tanto na agenda acadêmica quanto na política. O segundo é a contribuição de sua obra e pesquisas, que continuam lançando luz às questões analíticas fundamentais deste campo.

Carlos deixou o Brasil em 2005, década considerada pelos estudiosos do campo um momento de inflexão da temática racial do país. Os projetos de Ações Afirmativas, cujas propostas iniciaram-se ainda nos anos 1990, ganharam espaço na agenda governamental ${ }^{1}$.

Em 2003, foi criada a Secretaria de Promoção da Igualdade Racial; em 2004, o Programa Universidade para Todos (ProUni), culminando com a aprovação da Lei 12.711 de agosto de 2012, que dispõe sobre o ingresso nas universidades federais e nas instituições federais de ensino técnico de nível médio, estabelecendo cotas raciais para essas instituições. Em entrevista concedida a Antônio Sérgio Guimarães para a revista Tempo Social, ao ser perguntado sobre seu apoio às Ações Afirmativas, Carlos Hasenbalg deu a seguinte resposta: 
Estranho seria se quem pesquisou e denunciou as desigualdades raciais no Brasil durante mais de vinte anos não apoiasse o sistema de cotas e programas como o ProUni.

$[\ldots]$

A primeira razão de peso para ser favorável a essas políticas tem a ver com o papel crucial da educação no processo de mobilidade social. No último trabalho com o Nelson sobre esse tema, exploramos esse papel da educação nas diferenças raciais de mobilidade ocupacional no Brasil.

O efeito esperado das políticas de cotas raciais nas universidades públicas e de vagas para alunos de famílias carentes nas universidades privadas, incluindo pretos e pardos, por meio do ProUni, é o aumento da presença de não brancos em posições sociais de destaque. Isso, por sua vez, deverá socavar os estereótipos negativos que, como já mencionei, delimitam os "lugares apropriados" para os não brancos. Trata-se de acelerar significativamente a incorporação de não brancos em papéis que propiciem modelos de identificação (role models) (Guimarães, 2006:266-267).

Este cenário trouxe a público uma polêmica discussão sobre um tema que Carlos Hasenbalg sempre refletiu: a dinâmica entre raça e classe no Brasil. Seria a exclusão racial dos negros dos patamares sociais mais altos devido à sua situação racial ou apenas por sua condição de classe? Seria a sobreposição de raça e classe resultante de fatores históricos ou a condição racial era um fator de exclusão social? Essas perguntas, que têm soado como novidade aos ouvidos de muitos, estiveram presentes por décadas na obra de Carlos Hasenbalg.

\section{A TRAJETÓRIA}

Carlos Hasenbalg cursou a graduação em Sociologia na Universidade de Buenos Aires, o mestrado na Facultad Latinoamericana de Ciencias Sociales (Flacso) e o doutorado em Berkeley, sob a orientação de Robert Blauner. Em 1978, defendeu a tese Race Relations in Post-Abolition Brazil: The Smooth Preservation of Racial Inequalities, que deu origem ao livro Discriminação e Desigualdades Raciais no Brasil, publicado em $1979^{2}$. Carlos dedicou sua vida intelectual a compreender o Brasil e a preservação da desigualdade racial, como indica o título de sua tese de doutorado. 
Entretanto, sua contribuição ao tema não se limitou às suas próprias investigações e publicações, que serão tratadas adiante. Ele foi uma peça fundamental na formação de pesquisadores, em especial de pesquisadores negros, e na consolidação de um campo de estudos sobre raça no Brasil. Destaco alguns momentos.

Com apoio da Fundação Ford, que na época tinha Peter Fry como seu representante, Carlos assumiu, em 1986, a direção do Centro de Estudos Afro-Asiáticos (CEAA), o mais importante centro sobre a temática racial no país. O Afro, como era chamado, tinha uma excelente biblioteca para os padrões nacionais, recebia importantes pesquisadores internacionais, assim como contribuiu de inúmeras formas para a valorização da produção nacional sobre o tema. Dentre elas, pode-se destacar a reformulação da Revista Estudos, publicada desde 1977, que chegou a receber a conceituação máxima concedida a revistas científicas brasileiras. Foi sob sua gestão que foi publicado, em 1991, Escravidão e Relações Raciais no Brasil: Cadastro da Produção Intelectual (1970-1990), organizado por Luiz Claudio Barcelos, Olivia Maria Gomes da Cunha e Tereza Cristina Nascimento Araújo. Em tempos em que não havia acesso à internet, este cadastro foi um importante instrumento de divulgação da produção sobre o tema.

Outro marco de sua gestão foi o Concurso de Dotações sobre o Negro do Brasil que durante uma década promoveu editais anuais para dar apoio financeiro às pesquisas de jovens estudantes de pós-graduação e a pesquisadores. Ganhar o concurso de dotações do Afro tornou-se, na época, um diferencial de formação. Havia ainda a atividade de formação de jovens pesquisadores dentro do Afro, boa parte deles trabalhando em pesquisas com Carlos e Nelson. Um dos projetos foi o Laboratório de Pesquisa sobre Desigualdades Raciais, que ambos coordenaram. Segundo o próprio Hasenbalg, "Esse programa de treinamento de pesquisadores objetivou fazer um diagnóstico do desempenho socioeconômico dos grupos raciais por ocasião do centenário da abolição, utilizando, sobretudo, os dados da PNAD de 1987 que foram publicados no volume Cor da População" (1992a:5).

Os temas das pesquisas foram demografia, seletividade conjugal, educação, mercado de trabalho e gênero e raça. Seus resultados apontaram avanços importantes nas condições da população brasileira, permanecendo, no entanto, uma forte desigualdade de renda e racial. Complementando sua vocação de formação, o Afro estabeleceu uma parceria 
muito profícua com o Núcleo da Cor do Instituto de Filosofia e Ciências Sociais (IFCS) da Universidade Federal do Rio de Janeiro (UFRJ), coordenado por Yvonne Maggie. A presença constante de alunos do IFCS no Afro redundou em atividades coletivas como "Encontro Macumba", seminários mensais nos quais alunos de pós-graduação e professores convidados apresentavam suas pesquisas. Os seminários também eram o espaço de interlocução com o Movimento Negro, algo que sempre foi muito caro ao Carlos. Sua trajetória intelectual foi marcada pela proximidade com a militância, participando e promovendo eventos de interlocução. No diálogo com os pares, Carlos participou ativamente dos Grupos de Trabalho da Associação Nacional de Pós-Graduação e Pesquisa em Ciências Sociais (Anpocs) relacionados ao tema, como os GTs "Temas e Problemas da População Negra" e "Relações Raciais e Etnicidade", tendo sido um de seus coordenadores.

Durante todo o período em que esteve no Brasil e à frente do CEAA, Carlos sempre atuou como professor do antigo Instituto Universitário de Pesquisas do Rio de Janeiro (Iuperj), atual Instituto de Estudos Sociais e Políticos (IESP) da Universidade do Estado do Rio de Janeiro (UERJ). Lecionou cursos variados sobre Sociologia e, em particular, sobre o tema das desigualdades, além de formar diversos mestres e doutores na temática racial, desigualdades sociais, com especial atenção ao tema da educação. O Iuperj/IESP-UERJ sempre foi seu porto seguro no Brasil; o lugar a partir do qual ele pôde construir toda sua obra e fazer grandes amigos, como o nosso querido Cesar Guimarães.

\section{A TESE DE CARLOS HASENBALG E SEUS ESCRITOS POSTERIORES}

Não cabe aqui uma resenha do livro e da obra de Carlos. Meu intuito é apenas registrar alguns aspectos do trabalho que fizeram do livro Discriminação e Desigualdades Raciais um divisor de águas na literatura sobre o tema, reverberando em seus próprios trabalhos em parceria com Nelson do Valle Silva e na formação de uma nova geração de pesquisadores.

Vejo pelo menos três grandes características que fazem de Discriminação e Desigualdades Raciais no Brasil uma leitura obrigatória. Em primeiro lugar, o livro parte de uma incursão importante nos paradigmas teóricos da relação senhor / escravo e do processo de transição para a liberdade para uma análise das relações raciais pós-emancipação. $\mathrm{O}$ destaque dado no livro ao diálogo com as teses sobre escravidão foi a forma encontrada por Carlos para consolidar sua interpretação crítica 
à orientação teórica que explicava as relações raciais contemporâneas como uma sobrevivência do passado escravista. Carlos sempre foi categórico ao afirmar que, para entender a estratificação racial e os mecanismos que reproduzem as desigualdades raciais, era necessário abandonar a ideia de legado, ou, pelo menos, tirar a ênfase desta explicação. Entretanto, ele reconhece a existência de um legado do escravismo, localizado no analfabetismo maciço, na limitada diversificação de habilidades ocupacionais e na grande concentração demográfica em áreas rurais subdesenvolvidas, sendo o tema das desigualdades regionais uma preocupação constante na sua obra.

Esta crítica foi o caminho encontrado pelo autor para construir outra grande contribuição de seu livro: sua oposição à perspectiva que postulava uma incompatibilidade entre industrialização e racismo. Carlos defendia que a industrialização não eliminara a adscrição racial como critério que estrutura as relações sociais. Esta crítica impactou muitos trabalhos nas gerações seguintes.

O terceiro aspecto que destaco no livro é o brilhante exercício sociológico que Carlos realiza ao tratar da relação entre sistema de estratificação social, a estrutura de classes e raça, dialogando com autores clássicos da Sociologia. Argumenta novamente que raça não deve ser entendida como um critério subordinado na explicação da posição dos não brancos na estrutura de classes e no sistema de estratificação social. Ela deve ser analisada como atributo independente e associada a outras dimensões, tais como aspectos demográficos (distribuição regional dos grupos de cor e política migratória), educação, mercado de trabalho e ocupação, mobilidade social. No restante do livro, ele se debruça à tarefa de demonstrar esses aspectos, e termina fazendo considerações ao debate sobre raça e política no Brasil, tratando de identidade racial e das armas ideológicas a serem enfrentadas para combater a discriminação. O critério racial é determinante no preenchimento de posições na estrutura de classes. Carlos defendia que, para alterar esta situação, seria necessário não apenas apostar na lógica inerente ao desenvolvimento da sociedade de classes, mas principalmente, na atuação de fatores políticos de mobilização dos não brancos e das divisões no grupo dominante para que as desigualdades raciais fossem de fato enfrentadas.

Este trabalho deu origem a uma tradição de estudos sobre desigualdades raciais que tem procurado analisar suas causas, efeitos, bem como formas de mensuração a partir da associação com variáveis considera- 
das fundamentais (principalmente sexo, idade, educação, região) para entender o peso da variável raça / cor na distribuição desigual de recursos e de oportunidades.

Em Estrutura Social, Mobilidade e Raça, trabalho publicado em 1988 em coautoria com Nelson do Valle Silva, os autores elaboram um interessante modelo de análise, o modelo de realização socioeconômico, desenvolvido no artigo "Cor e Processo de Realização Socioeconômica". Nele, os autores demonstram que cada etapa do ciclo de vida tende a produzir um impacto causal nas etapas seguintes, chegando a ter, em algumas situações, uma feição de cumulação de desvantagens. Esse modelo está ampliado no último livro publicado pelos autores, Origens e Destinos: Desigualdades Sociais ao Longo da Vida, no qual eles apontam diferentes etapas do ciclo de vida e identificam as dimensões que devem ser observadas em cada uma delas. O ciclo inicia-se com a origem familiar - onde se observam a situação social das famílias e os recursos disponíveis a seus membros, fundamentais para a trajetória socioeconômica dos indivíduos. Na fase seguinte considera-se a internalização de recursos, etapa em que devem ser observadas as condições e possibilidades nas quais crianças e adolescentes dessas famílias iniciam sua trajetória social. A terceira e quarta fases correspondem à autonomização de status - momento em que o jovem começa a adquirir status social próprio, marcada pelo ingresso no mercado de trabalho - e a realização de status definida a partir da posição dos indivíduos na estrutura sócio-ocupacional e da distribuição da renda. Este ciclo gera determinadas condições de renda familiar e pobreza que culminam no momento no qual voltamos ao estágio inicial do ciclo (Hasenbalg e Silva, 2003).

Creio que na agenda de estudos de Carlos sobre desigualdades, o tema da educação sempre recebeu uma atenção particular. Segundo ele, a educação é central para entender a produção e a reprodução das desigualdades entre brancos e não brancos. Não é possível tratar deste tema sem citar o brilhante artigo "Tendências das Desigualdades Educacionais no Brasil", escrito por ele e por Nelson e publicado pela DADOS - Revista de Ciências Sociais em 2000. Utilizando os dados das PNADs sobre educação para os anos de 1976, 1986 e 1998, os autores apontam para um significativo crescimento da escolaridade média da população brasileira que favoreceu, principalmente, as coortes de idade mais jovens. No que diz respeito às desigualdades raciais, o estudo aponta para uma ligeira convergência educacional entre brancos e não brancos. Todavia, segundo os autores, as diferenças educacionais dos 
grupos de cor não serão eliminadas até que ocorra uma igualação das oportunidades de acesso de brancos e não brancos aos níveis de ensino mais elevados. Destaca-se, ainda, um importante achado para o debate sobre o sistema escolar brasileiro. Segundo eles,

O exercício da decomposição dos fatores explicativos da melhoria educacional proposto neste trabalho sugere, como estimativa conservadora, que aproximadamente $60 \%$ dessa melhoria é devido à mudança nas condições de vida e à distribuição geográfica das famílias, decorrente da urbanização e da transição demográfica, devendo-se os $40 \%$ restantes às melhorias efetivas no desempenho do sistema educacional. Destaca-se, finalmente, que nestas duas décadas finais do século a elevação do patamar educacional, junto com a diminuição das desigualdades educacionais, não foram acompanhadas por uma elevação do nível de renda e uma melhoria na sua distribuição (Hasenbalg e Silva, 2000:18).

Mercado de trabalho é outro tema de destaque nas reflexões de Carlos Hasenbalg. No texto "O Negro na Indústria: Proletarização Tardia e Desigual", analisando a inserção do negro no incipiente processo de industrialização no Brasil, aponta que a competição desigual da população negra com os imigrantes nas regiões industrialmente mais desenvolvidas e sua concentração nas regiões economicamente menos dinâmicas levaram à sua incorporação tardia e subordinada ao mundo industrial-urbano. O processo de industrialização e urbanização, migrações internas, o desenvolvimento urbano-industrial e fortes diferenças regionais são fatores importantes na caracterização da proletarização da população negra, que se beneficiou muito pouco das melhorias socioeconômicas. Segundo ele, tais achados derrubam as teorias que associavam a diluição das diferenças raciais como efeito do desenvolvimento e da modernização. O mercado de trabalho atua também como um repositor de desigualdades raciais, uma vez que o mesmo investimento em educação e experiência produz retornos desiguais para brancos e não brancos, evidenciando uma discriminação no mercado de trabalho.

A articulação entre educação e mercado de trabalho é analisada através da mobilidade social. Os resultados de suas investigações apontam que para além do fato dos não brancos obterem níveis de escolaridade inferiores aos brancos de mesma origem social, os retornos à escolaridade adquirida em termos de inserção ocupacional e renda tendem a ser proporcionalmente menores para este grupo. Desde seu primeiro livro, conclui que a origem social não é o único determinante 
explicativo das diferenças entre os grupos de cor, pois com a mesma origem social dos brancos, os não brancos têm oportunidades educacionais mais limitadas e os ganhos educacionais são traduzidos em distintos ganhos ocupacionais e de renda.

Vale registrar ainda que, embora o destaque dado neste relato tenha sido para os estudos sobre desigualdades raciais, Hasenbalg publicou importantes trabalhos nos quais analisa o campo de pesquisa sobre desigualdades e relações raciais, além de questões relacionadas à política e mobilização política (Hasenbalg, 1992b; 1988).

\section{O LEGADO DE HASENBALG E A AGENDA DE ESTUDOS SOBRE RAÇA NO BRASIL}

Encerro este breve relato sobre a trajetória de Carlos Hasenbalg propondo uma reflexão sobre os desafios da agenda da temática racial no Brasil citando mais um trecho da entrevista concedida a Antônio Sérgio Guimarães:

[...] naquele livro de 1979, atribuía as desigualdades entre os grupos de cor ou raciais à discriminação racial e ao racismo. Cabe aclarar que, nesse livro e nos trabalhos posteriores com o Nelson, a discriminação não é observada diretamente. Ela é inferida a partir da análise da disparidade de resultados sociais dos grupos de cor, controlada pelas variáveis relevantes.

$[\ldots]$

As diferenças de desempenhos de brancos e não brancos são sempre observadas usando as variáveis de controle pertinentes, ou seja, a igualdade de outras condições, tais como origem social, renda familiar e nível educacional. Esses controles permitem tirar conclusões sobre as diferenças na apropriação de oportunidades sociais pelos grupos de cor ou raciais. Em todos os temas analisados durante mais de vinte anos, os não brancos acabam em desvantagem (Guimarães, 2006:260)

Há dois aspectos importantes nesta entrevista que retomo aqui a título de agenda. O primeiro diz respeito aos avanços e limites analíticos da perspectiva quantitativa para identificar e medir a discriminação. $\mathrm{O}$ segundo aspecto é como estabelecer a relação entre discriminação e desigualdades raciais.

Acredito que o primeiro passo seja tratar desta agenda envolvendo estudos quantitativos e qualitativos. Desigualdades raciais e discrimina- 
ção racial, embora estejam fortemente entrelaçados, nos conduzem a diferentes desafios empíricos e analíticos. Em relação às desigualdades raciais, os dados, como nos demonstrou Carlos, são inequívocos e apontam para um processo cumulativo de desvantagens socioeconômicas que coloca a população negra na base da pirâmide social e com maiores dificuldades de ascensão. A partir da seleção de variáveis consideradas fundamentais para entender o peso da condição racial no acesso a recursos e oportunidades, os estudos atuais têm se beneficiado do avanço das técnicas estatísticas. Elas propiciaram um importante refinamento do controle de variáveis, permitindo perceber de forma mais acurada que raça/cor é, sim, um atributo que atua nas chances de vida dos indivíduos. As investigações recentes são unânimes em reafirmar os achados de Carlos, às vezes sem assumir como ele o fez, a relação entre discriminação e desigualdades. Os negros que conseguem furar a barreira da escolaridade enfrentam maiores dificuldades para obter as mesmas posições que os brancos com condições educacionais similares. A rigidez racial cresce paulatinamente com as tentativas de aquisição de status (Ribeiro, 2006).

Creio que as pesquisas qualitativas sobre raça enfrentam desafios de outra natureza. Em muitas situações de pesquisa, obter do entrevistado um relato de preconceito ou nomear como racismo determinadas situações e experiências não ocorre de forma tão inequívoca quanto nas análises de dados. Enquanto os dados nos falam de grupos, o cotidiano nos fala de experiências individuais de discriminação, em contextos específicos.

Dessa forma, os esforços em conciliar abordagens quantitativas e qualitativas têm sido uma saída interessante para melhorar a compreensão e aferição das desigualdades raciais. Os achados quantitativos constituem um ponto de partida fundamental para os estudos qualitativos, pois muitas respostas para as desigualdades aferidas estatisticamente precisam ser observadas sob uma perspectiva complementar.

Destaco dois exemplos extremos: os estudos sobre mobilidade e sobre pobreza. As abordagens qualitativas demonstram que há mais relatos de discriminação entre os indivíduos em processos de ascensão do que entre os indivíduos em situações de pobreza. Aqui, as abordagens quantitativas e qualitativas se complementam e chegam às mesmas conclusões (Figueiredo, 2003). Ao pensar a questão racial em situações de pobreza (em que a maioria da população investigada é negra), po- 
demos identificar ao menos duas perspectivas para observação: i) olhar a situação dos negros no espaço de pobreza como resultado de uma condição de desigualdade racial, e ii) observar as relações raciais entre negros e brancos vivendo num mesmo espaço de pobreza e perceber como a raça/cor os diferencia ou não neste contexto. Nota-se, então, que diferenças na posição social geram diferenças de percepção e de experiência de discriminação racial (Lima, 2001). Da mesma forma que o atributo racial pode evidenciar distinções entre negros e brancos numa mesma condição social, esta última pode evidenciar diferenças de percepção entre indivíduos da mesma cor/raça.

Creio que o ponto principal para esta agenda é tentar compreender a relação entre ordem biográfica e ordem societária fortemente evidenciada por esses temas. Estamos diante de experiências individuais construídas a partir de valores fortemente estruturados pela sociedade. Nesse sentido, ao falar de trajetórias, projetos e escolhas, relatamse experiências individuais que se dão num campo de possibilidades em que as características individuais se articulam de modo complexo com características estruturais. São trajetórias individuais construídas a partir de marcas sociais distintas e, às vezes, sobrepostas.

Por fim, acrescento a esta agenda de estudos um tema que não foi tratado por Hasenbalg diretamente, mas que apareceu em alguns de seus trabalhos que discutem a questão política. Os estudos sobre as Ações Afirmativas transformaram a agenda deste campo tanto pelo impacto causado pelo debate quanto pelo aumento de estudantes negros nas universidades, trazendo seu interesse pelo tema e ampliando a demanda por formação na temática racial. Carlos nos deixou um belo legado e uma enorme tarefa.

(Recebido para publicação em novembro de 2014) (Aprovado para publicação em dezembro de 2014) 


\section{Márcia Lima}

\section{NOTAS}

1. Carlos Hasenbalg chegou a participar do seminário internacional "Multiculturalismo e Racismo: O Papel da Ação Afirmativa nos Estados Democráticos Contemporâneos", promovido pelo Ministério da Justiça, em 1996. O seminário contou com a presença de estudiosos e militantes estrangeiros e brasileiros, e marcou o início do debate sobre Ações Afirmativas no Brasil. Carlos apresentou o texto "O Contexto das Desigualdades Raciais no Brasil".

2. Vale registrar que seu parceiro intelectual Nelson do Valle Silva defendeu seu doutorado um ano antes em Michigan, com a tese Black-white Income Differentials: Brazil-1960.

\section{REFERÊNCIAS BIBLIOGRÁFICAS}

BARCELOS, Luiz Claudio; GOMES, Olivia e ARAÚJO, Teresa. (1991), Escravidão e Relações Raciais no Brasil: Cadastro da Produção Intelectual (1970-1990). Rio de Janeiro, Centro de Estudos Afro-Asiáticos.

FIGUEIREDO, Ângela. (2003), A Classe Média Negra Não Vai ao Paraíso: Trajetórias, Perfis e Negritude entre os Empresários Negros. Tese de doutorado em Sociologia, Iuperj, Rio de Janeiro.

GUIMARÃES, Antônio Sérgio. (2006), "Entrevista com Carlos Hasenbalg”. Tempo Social, vol. 18, no 2, pp. 259-268.

HASENBALG, Carlos. (1979), Discriminação e Desigualdades Raciais no Brasil. Rio de Janeiro, Graal.

. (1992a), "Apresentação do Dossiê Laboratório de Pesquisa sobre Desigualdades Raciais". Estudos Afro-Asiáticos, no 23, pp. 5-6.

(1992b), “O Negro na Indústria: Proletarização Tardia e Desigual”, in N. V. Silva e C. Hasenbalg, Relações Raciais no Brasil Contemporâneo. Rio de Janeiro, Rio Fundo Editora.

e SILVA, Nelson do Valle. (1987), “Industrialization, Employment and Stratification in Brazil", in J. Wirth; E. Nunes e B. Bogenschild (orgs.), State and Society in Brazil: Continuity and Change. Boulder, Colorado, Westview Press, vol. 1, pp. 110-135.

. (1988), Estrutura Social, Mobilidade e Raça. Rio de Janeiro, Vértice.

(2003), Origens e Destinos: Desigualdades Sociais ao Longo da Vida. Rio de Janeiro, Iuperj/UCAM/Topbooks/Faperj.

LIMA, Márcia. (2001), Serviço de Branco, Serviço de Preto: Representações sobre Cor e Trabalho no Brasil. Tese de doutorado, IFCS/UFRJ, Rio de Janeiro.

RIBEIRO, Carlos Antonio Costa. (2006), “Classe, Raça e Mobilidade Social no Brasil”. DADOS - Revista de Ciências Sociais, vol. 49, no 4, pp. 833-873.

SILVA, Nelson do Valle e HASENBALG, Carlos. (2000), “Tendências da Desigualdade Educacional no Brasil". DADOS-Revista de Ciências Sociais, vol. 43, no3, pp. 423-445. 
A Obra de Carlos Hasenbalg e seu Legado à Agenda de Estudos...

\section{Artigos de Autoria de Carlos Hasenbalg Publicados em DADOS -} Revista de Ciências Sociais

HASENBALG, Carlos A. (1968), “Empresários e Desenvolvimento Econômico”, no 4, pp. $5-31$.

. (1977), “Desigualdades Raciais no Brasil”, no 14, pp. 7-33.

(1979), “Gino Germani: 1911-1979”, no 22, pp. 3-4.

. (1984), “Comentários à ‘Raça, Cultura e Classe na Integração das Sociedades', de Helio Jaguaribe", vol. 27, no 3, pp. 395-398.

. (1995), “Entre o Mito e os Fatos: Racismo e Relações Raciais no Brasil”, vol. 38, no-2, pp. 355-374.

e BRIGAGÃO, Clóvis. (1971), “Formação do Empresário Financeiro no Brasil”, no 8, pp. 79-103.

HASENBALG, Carlos e SILVA, Nelson do Valle. (2000), “Tendências da Desigualdade Educacional no Brasil", vol. 43, no 3, pp. 423-445. 


\title{
Márcia Lima
}

\section{RESUMO}

A Obra de Carlos Hasenbalg e seu Legado à Agenda de Estudos sobre Desigualdades Raciais no Brasil

Este texto, escrito como uma homenagem póstuma a Carlos Hasenbalg, traz o relato da trajetória profissional e intelectual do autor, dividido em três momentos. O primeiro destaca sua importância na consolidação do campo de investigação sobre desigualdades raciais no Brasil, atuando tanto na agenda acadêmica quanto política. O segundo, as contribuições de sua obra demonstrando como seu pensamento e seus achados empíricos continuam lançando luz a questões analíticas centrais para os estudos das desigualdades raciais. $\mathrm{O}$ terceiro aponta alguns desafios teóricos e metodológicos para os estudiosos das desigualdades raciais no Brasil.

Palavras-chave: Carlos Hasenbalg; desigualdades raciais; relações raciais

\begin{abstract}
The Work of Carlos Hasenbalg and his Legacy for the Study of Racial Inequalities in Brazil

As part of a posthumous tribute to Carlos Hasenbalg, this text is an account of his professional and intellectual trajectory and is divided into three parts. The first one highlights his importance in the consolidation of the field of investigation concerning racial relations in Brazil, in which he influenced both the political and academic agenda. The second one stresses his contributions to the field by pointing out how his thought and empirical findings still shed light upon key analytical questions. The third section outlines some theoretical and methodological challenges that researchers of racial inequalities in Brazil ought to tackle.
\end{abstract}

Keywords: Carlos Hasenbalg; racial inequalities; racial relations 
A Obra de Carlos Hasenbalg e seu Legado à Agenda de Estudos...

\section{RÉSUMÉ}

L'Oeuvre de Carlos Hasenbalg et son Héritage pour l'Agenda d'Études sur les Inégalités Raciales au Brésil

Le texte, écrit comme un hommage posthume à Carlos Hasenbalg, présente le récit de la carrière professionnelle et intellectuelle de l'auteur, divisé en trois étapes. La première souligne l'importance de l'intellectuel dans la consolidation du domaine de recherche sur les inégalités raciales au Brésil, agissant à la fois dans l'agenda académique et dans la politique. La deuxième décrit les contributions de son travail démontrant comment sa pensée et ses résultats empiriques continuent d'apporter de la lumière aux questions analytiques pour les études des inégalités raciales. La troisième signale les défis théoriques et méthodologiques pour les chercheurs des inégalités raciales au Brésil.

Mots-clés: Carlos Hasenbalg; inégalités raciales; relations interraciales

\section{RESUMEN}

La Obra de Carlos Hasenbalg y su Legado para los Estudios sobre Desigualdades Raciales en Brasil

Este texto, escrito a modo de homenaje póstuma a Carlos Hasenbalg, traza el relato de la trayectoria profesional e intelectual del autor, dividido en tres momentos. El primero de ellos subraya su importancia en la consolidación del campo de investigaciones sobre desigualdades raciales en Brasil, actuando tanto en la agenda académica cuanto en la agenda política. En segundo lugar, se discuten las contribuciones de su obra demostrando cómo su pensamiento y sus hallazgos empíricos siguen arrojando luz a cuestiones analíticas centrales para el estudio de las desigualdades raciales. Finalmente, la tercera parte del texto apunta algunos desafíos teóricos y metodológicos para los estudiosos de las desigualdades raciales en Brasil.

Palabras clave: Carlos Hasenbalg; desigualdades raciales; relaciones raciales 